University of Wollongong

Research Online

Faculty of Engineering and Information

Faculty of Engineering and Information

Sciences - Papers: Part A

Sciences

$1-1-2016$

Revisiting an information infrastructure for development: exploring the cost of information in Pacific Island development

William J. Tibben

University of Wollongong,wjt@uow.edu.au

Follow this and additional works at: https://ro.uow.edu.au/eispapers

Part of the Engineering Commons, and the Science and Technology Studies Commons

Research Online is the open access institutional repository for the University of Wollongong. For further information contact the UOW Library: research-pubs@uow.edu.au 


\title{
Revisiting an information infrastructure for development: exploring the cost of information in Pacific Island development
}

\author{
Abstract \\ Information and communication technologies (ICTs) have been associated with development \\ programmes for many decades. A theme of Lamberton's commentary on such initiatives focuses on the \\ lack of attention given to information as a key factor in the development process. His writing reiterated a \\ number of arguments that he saw as being fundamental to the application of an information perspective \\ to development issues. With a focus on agricultural development policy in the Pacific region, the paper \\ uses a number of propositions that are suggested by Lamberton to analyse contemporary development \\ initiatives in Pacific Island agriculture. These propositions focus attention on information costs that can \\ influence the transfer of information and development of knowledge. Document analysis of selected \\ published sources from a Pacific Island development programme are reviewed to illustrate the \\ significance of information costs for development processes. The paper addresses the contention \\ between traditional authority and knowledge and its significance for development.
}

\section{Keywords}

exploring, cost, pacific, island, information, revisiting, infrastructure, development

\section{Disciplines}

Engineering | Science and Technology Studies

\section{Publication Details}

Tibben, W. (2015). Revisiting an information infrastructure for development: exploring the cost of information in Pacific Island development. Prometheus: critical studies in innovation, 33 (4), 375-393. 


\section{Revisiting an information infrastructure for development: exploring the cost of information in Pacific Island development}

William Tibben

University of Wollongong, Wollongong, NSW, Australia

Information and communication technologies (ICTs) have been associated with development programs for many decades. A theme of Lamberton's commentary on such initiatives focused on the lack of attention given to information as a key factor in the development process. His writing reiterated a number of arguments that he saw as being fundamental to the application of an information perspective to development issues. With a focus on agricultural development policy in the Pacific region, the paper uses a number of propositions that are suggested by Lamberton to analyse contemporary development initiatives in Pacific Island agriculture. These propositions focus attention on information costs that can influence the transfer of information and development of knowledge. Document analysis of selected published sources from a Pacific Island development program are reviewed to illustrate the significance of information costs on development processes. The paper addresses the contention between traditional authority and knowledge and its significance for development.

\section{Email: wjt@uow.edu.au}




\section{Introduction}

Don Lamberton's work has done much to improve understanding of social development issues (Lamberton, 1996a, 1996b, 1998, 2001). Bringing an information perspective to bear on development was considered critical to not only a better understanding of the sizeable investments in telecommunications that were being made in low and middle income countries but also of the improvements that ultimately lift people out of poverty. Even though an economist, Lamberton never considered economics as an end itself. His own humble upbringing in rural New South Wales meant that he never lost sight of the impact economics has on the lives of people including the poorest in society (Macdonald \& Nightingale, 1999).

He routinely expressed reservations about the lack of economic scholarship surrounding investments in technology which was assumed by orthodox theory to be exogenous to the economic system (Lamberton, 1994, 2001). His fundamental proposition was that the root of the technology problem, along with an unquestioning faith in markets rested with the discipline's poor appreciation of the role that information plays in the economy. Along with the standard preoccupation pertaining to people's preferences and wants, Lamberton (2001) wanted economists to ask the question what do people know?

Technology has changed significantly since Lamberton wrote his last contributions to development debates. Telecommunications has been disambiguated into terms such as Internet, broadband, mobile, social media and Web 2.0. However, Lamberton's information-based analysis is hardly defined by the technology of the time and, as such, provides analytical constructs that have potential for application today.

The paper is structured in the following way. It firstly provides a broad outline of the main theoretical issues that an information-perspective brings to development. In order to establish a context for the analysis the paper turns its attention to development issues in the Pacific region with a particular focus on agriculture. The paper uses one of Lamberton's earlier contributions with Jussawalla and Karunaratne to the development debate in the Pacific to provide a number of analytical constructs in the form of information costs(Jussawalla et al., 1988). These constructs are subsequently illustrated in the analysis of case material. The paper concludes with a discussion about the significance of information costs in the formulation of development policy.

\section{An information infrastructure for development}

In one of his latter contributions to the development debate prior to retiring, Lamberton's (2001) paper in Prometheus titled an Information Infrastructure for Development summarises his thoughts on this topic. He asks the reader to consider an information perspective when considering the role of telecommunications technology in development. He expresses some regret that 
information economics has not played a greater part in setting an agenda for the 'new economy' which has promoted investments in telecommunications (p. 223). He judged the rhetoric that justified these large flows in foreign direct investment (FDI) as a reflection of how this debate had been captured by specific interests rather than academic scholarship (Lamberton, 2001, p. 225).

Lamberton's grievances with development policies have their origin in his disappointment with economics as a discipline. The limitations of the market system and acceptance of exogenous technological change are the fundamental problems that he identifies (Lamberton, 2001, p. 223). Assuming information is a commodity, or worse still, a public good, enables these two articles of faith to be maintained. The market system and technology come under pressure when the economic characteristics of information are scrutinised more deeply.

Lamberton summarises these unusual characteristics by pointing out three attributes that shape information use within the economy: its capital-like attributes (as opposed to commodity; indivisibilities; and complementarities (Lamberton, 2001, p. 224). He draws on Schumpeter's explanations of capital to emphasise the structural relations of information - in much the same way that people can understand the relationship between cars and roads, information has similar structured relationships he argues. This leads to the notion that indivisibilities are a natural outcome of these structured relations. This further leads on to complementarities.

Lamberton uses this brief explanation to criticise efforts at the time to justify significant investments in telecommunications in the name of development. He singles out the International Telecommunications Union (ITU) and the World Bank as promoting a mere assertion that telecommunications leads to economic growth (Lamberton, 2001, p. 225). He notes that telecommunications investments and policy changes in the area suited business, government and some international agencies and so were vigorously pursued as part of the foreign aid and FDI agenda. While he notes that some attention is given to soft technology, he complains that the treatment of education and training, for example, requires further elaboration (Lamberton, 2001, p. 226). Missing are the time dependant changes that an information perspective emphasises such as individual learning, organisational learning and cultural change.

In relation to the digital divide, Lamberton was one of the first to observe that it is a multi-faceted concept and recommends caution when formulating development strategies (Lamberton, 2001, pp. 226-227). The idea that the economic modelling of advanced countries could be applied to low and middle income countries revealed a poor appreciation of the complexities in the latter:Downloading of technology is ill-conceived as a solution to the digital divide because that divide is an extremely complex notion that cannot be reduced to a single dimension, be it income or Internet access. (Lamberton, 2001, p. 227) 
Part of the remedy from Lamberton's perspective was a better appreciation of information as an economic resource with specific characteristics. He uses Arrow's description of information being a 'fugitive resource"' (Lamberton, 2001, p 227). Lamberton saw the attempts to fit information into the narrow definitions of Trade Related Intellectual Property regimes of the time as not only ignorant of unusual economic characteristics of information but which also had significant implications for indigenous knowledge in rich and poor countries alike.

Another important consideration from Lamberton's perspective was the ability of countries to absorb new information and technology (Lamberton, 2001, p. 227). He warned that the rapid pace of technological change may not be readily absorbed by some countries because of their existing capabilities to process and use new information. Lamberton asserts that these challenges are far too complex for the invisible hand of the market system to rectify. The implications are more than theoretical because of the consequent impacts on both labour and suppliers are significant. He singles out the management profession as being in particular need of assistance from an information economics perspective.

Lamberton concludes his paper by advising readers to move their attention from information technology to information. The outcomes are dramatic: solution to the productivity paradox; and full informatisation of society revealed leading to a more accurate understanding of the information society. Rather than advocating the standard input-output analysis of telecommunications of the time, he exhorted researchers to look more closely at information processes.

Attention has to shift to the comprehension of messages, learning processes, and utilization of information in sequential processes of learning, questioning, unlearning, and application (Lamberton, 2001, p. 228).

Assumptions must now recognise information as a structured quantity like capital. Recognition of indivisibilities and complementarities will make a significant improvement in development policy.

\section{Pacific Island development policy - a struggle of knowledge and authority}

The vignette that follows highlights a link between technology and authority.

\section{Vignette}

A new item of plant equipment supplied by an Australian aid program for the Public Works Department(PWD) in a Pacific Island country had arrived by sea and was waiting at the wharf for transport to its new home in the PWD yards. The transport of the plant from wharf to final resting place was complicated by its height (the prospect of becoming entangled in overhead 
wires), and its weight, which just exceeded the capacity of the only bridge on route to the PWD yard. Faced with the prospect of damaging the only bridge on the main thoroughfare through the capital, chief engineer Tim Watts decided a safer option was to create a temporary piped earth bridge on a secondary route further upstream. This option was not welcomed by the Minister of Works who saw benefits in having this large piece of new infrastructure paraded down the main street of town in front of Saturday morning shoppers. The less risky route upstream took the plant on a less trafficked route away from the crowds. Even though the Chief Engineer was challenged on his decision by the Minister, his engineering judgement about risks convinced him that his plan for a temporary earth bridge was professionally correct even though unpopular.

On the morning of the transport the Minister made a last minute decision to change the route back to the main street even though preparations had been made for the transport of the plant upstream. The Chief Engineer explained the risks to the bridge but this reasoning failed to change the Minister's mind. The transport of the plant went ahead over the bridge and along the main street without any immediate impact on the bridge's structure. The Minister was able to not only enjoy the credit for the arrival of the new plant but also for his challenge to the judgment of the Australian Chief Engineer suggesting greater expertise in such matters. Tim Watts accepted the outcome with a shrug of the shoulders knowing that his first decision was correct and one he would make again given the same circumstances.

Aid projects can be a site of considerable conflict. Foreign experts on salaries many more times the wages of local counterparts often make demands for changes that run contrary to local norms and wants. Sometimes these experts can appear to get it wrong, confirming a perception that they are incompetent as well as overpaid.

a The link between knowledge and authority can have profound consequences for development programs. Arrow's (1974) monograph on the limits of organization draws links between information-use within organisations where expertise is found to confer authority. He reasons that the prospect of gaining consensus on the myriad of issues that need to be addressed on a daily basis has naturally led to the creation of organisations with authoritative structures in which those with the most expertise should be given authority to process and act on information on behalf of others.

Given the high reliance of countries and states in the South Pacific region on foreign aid, development policies have been dominated by foreign government agencies (e.g. Australia, New Zealand, USA, France, EU, China, Taiwan and Japan) as well as inter-government agencies (World Bank, Asian Development Bank and several UN agencies (such as the ITU and UNESCO) (Kelsey, 2004). When Lamberton (2001) wrote the article on development described in the previous section, many governments in the South Pacific where encouraged to sell their service arms, such as broadcasting and telecommunications, to the private sector (ADB, 2004). These development 
policies were heavily influenced by neo-liberal economic policy which asserts "the primacy of the [economic] market in social welfare" (Hall \& Midgley, 2004 p. $31)$. Reliance on the economic market mirrored changes in social policy around the world which can be traced to the leadership of Thatcher and Reagan during the 1980s (Pusey, 1991; Midgley, 2003).

With this greater focus on economic matters, South Pacific countries were called on to account for the generous per-capita aid flows into the region. Long run social and economic development indicators had remained static and in some cases have gone backwards (Hughes, 2003). With population growth of 3 per cent and economic growth running at 1 per cent, Hughes cites poor governance of aid projects as the root cause. More recent statistics tell a similar story (FAO, 2010).

Key neo-liberal economic tenants of entrepreneurialism, growth and privatisation have nonetheless met with resistance (Firth, 2006). For example, the narrative of the Pacific Way seeks to encapsulate Pacific Island values and practices as a model for development (Huffer, 2006). Rather than assuming a selfish individual entrepreneur as the key generator of worthwhile social activity, Pacific cultures generally subsume the interests of individuals in their emphasis of the extended family (Huffer, 2006). The Pacific Way was coined during the 1970's by Fiji's former statesman, Ratu Sir Kamisese Mara to describe traditional modes of decision making in the Pacific where a governing body of chiefs discuss matters with the view of achieving consensus.

Hence, it is with this background that development programs can become contentious. While those providing the funds and resource for development hold considerable sway over the design of aid and delivery of programs, its possible for resident actors to change aspects of these programs to suit local interests. This was a pattern that was established during colonial times and is still evident today (Hempenstall, 1978; Huffer, 2006).

The fractious nature of Pacific Island development is underpinned by a number of basic realities. Firstly, models of industrialisation that have traditionally been used to define development are inappropriate for Pacific Island states (Streeten, 1993). Pacific island economies are characterised by a number of factors that define differences with industrialised countries (FAO, 2010; Higgins, 1994). Some are distant from markets, have unsuitable natural resources, fragile eco-systems, small domestic markets, institutional and exhibit cultural resistance to change. 'Smallness' and isolation work against initiatives that rely on large volumes of resource inputs, economies of scale and organisations with suitable expertise. Political upheaval in Fiji and the Solomon Islands over the past decade has created further uncertainties for aid donors and potential investors .

Economies of small Pacific states are characterised by a narrow focus on primary production that are vulnerable to natural disasters such as cyclones and tsunamis (FAO, 2010). Another characteristic is the high proportion of activity in the informal subsistence sector of these economies. For example, in Fiji only 20 
per cent of adults worked in the formal economy and 46 per cent were economically inactive (UNDP, 1999).

One area in which the struggle between foreign imposed development mandates and local culture is revealed is in assistance to agriculture. Agriculture continues to play a very important part in the life of Pacific people with a majority of the population engaged in this activity (FA0, 2010). The Pacific has two regional organisations that play a significant roll in the development and dissemination of scientific knowledge and technological knowledge in Pacific agriculture. These are the University of the South Pacific's (USP) School of Agriculture and the South Pacific Community (SPC) (Tibben \& Tielu, 2007). At the national level, diffusion of scientific knowledge and innovation is through the extension services of government departments of agriculture. This reflects a common pattern of research and development where regional agencies rather than individual governments are active. While countries contribute to these regional agencies, the lion's share of support comes from regional and external sources such as Australia, New Zealand, US, France and the European Union (EU).

Ultimately the barriers that constrain dissemination of scientific knowledge are related to an understanding of the structure of agriculture. Generally, there are four broad categories of agriculture in the Pacific (Tibben \& Tielu, 2007). There are traditional staple root crops, the plantation crops, livestock and horticultural production. The later is dominated by fruit and vegetable production. Plantation and horticulture agricultural production which is commercially oriented, is more likely to draw on what science and technology has to offer to improve production, reduce costs and increase profits. The semi subsistence farmer may express an interest in what science and technology may offer if someone is able to pay for it or is provided with significant discounts. The subsistence farmer is likely to challenge any scientific threat to what his or her ancestors have taught through the ages. Since the last two types of agriculture dominate agriculture in the Pacific there is little incentive for small semisubsistence farmers to use modern techniques. Hence, Western experience in the diffusion of science and innovation in agriculture is largely out of touch to many farmers in the Pacific (Schwass, 1983).

Recent developments in agriculture suggest that private sector development has been responsible for promising commercial initiatives (FAO, 2010). Selected examples of nonu fruit production in Samoa, horticultural products in Fiji and natural cocoa products in Vanuatu all have their genesis in entrepreneurial activity rather than government mandate. An important component of these developments in Samoa has been the readiness of some communities to accommodate such activity within their traditional land tenure system. While still a far cry from enabling individual ownership by which property rights can be conferred, it is cited as an example where tradition can incorporate modern forms of entrepreneurial activity in agriculture.

In seeking to include culture in a development paradigm, Huffer (2006, p. 49) defines the research challenge. 
There has been little effort...to understand how communities can utilise their human and cultural resources to enhance livelihoods while participating in the market economy. Advocates of the market economy assume that it will provide answers and that people will adapt to it - they do not envision another more appropriate solution

The paper proceeds to investigate 'more appropriate solutions' using contemporary approaches to agricultural development in the South Pacific region as the focus. It establishes an analytical framework in the next section based on important aspects of an information perspective outlined by Lamberton.

\section{An information perspective on Pacific Island development}

In The Cost of Thinking in Ten Pacific Countries, Lamberton explored the potential that an information perspective can bring to development policy in Pacific-rim and Pacific-basin countries (Jussawalla et al., 1988). Only two countries from the South Pacific (basin) region were analysed - Fiji and Papua New Guinea. The study essentially was an "input-output" measures study misgivings that Lamberton did hint at in the book's preface. Lamberton (1988) explains that the costs of thinking referred to in the book's title is taken from a 1966 essay by Marschak (1966). Marschak defined these costs in terms of 'obtaining and processing of information to determine and carry out optimal strategies'. Lamberton saw great potential in Marschak's insights to throw light on the problems of development in the Pacific region. Essentially, he saw the roll of information economics in terms of minimising these costs to better facilitate development. The factors that contribute to information costs are elaborated in the following points he identifies (Lamberton, 1988).

Lamberton (1988) identified the following themes as contributing to information costs. For each of these factors I develop propositions. These in turn are related to the case study that follows.

\section{Information as capital}

As already alluded to, likening information to capital has implications for a number of aspects in development policy. While information may be a commodity in some circumstances it is not universally so. One attribute of capital used to justify information-as-capital relates to sunk investment costs. In order to be able to obtain and process information, a number of costs that cannot be recouped are expended which is more akin to capital than commodity. For example time spent on education, training or gaining experience are the kinds of costs that cannot be recouped if one decides to choose a different area of expertise development.

Another related feature of information-as-capital is that its cost of production is independent of the scale on which it is used. This essentially means 
that once efforts are made in acquiring information and developing capabilities to use information it can be used multiple times at marginal cost.

Another feature of information that likens it to capital is its structural qualities. Its not practical or even possible in some circumstances to isolate information into its constituent pieces because it is only useful if other pieces of information are available (Lamberton, 1998). The lesson for development strategists is that the transfer of some information is not sufficient to enable development to occur. This has been recognised in studies of tacit knowledge and explicit knowledge where explicit knowledge is only made productive if requisite stocks of tacit knowledge also exist (Lamberton, 1998). The ease of transfer of the former often means the latter is ignored.

Proposition: Information will display capital like characteristics, sunk costs impacting on capital such as risk (investment costs), economies of scale and complementarities.

\section{Costs to the individual}

This change in defining information from commodity to capital has significant implications for the individual. Given information's capital-like nature, the time that individuals are required to devote to learning new techniques and concepts incurs opportunity costs which cannot be recouped if things do not work out. Given such uncertainties the costs that can be incurred by individuals in their use of information can act as disincentive. Some of these uncertainties include the following questions: will the time taken to learn new ideas lead to improvement? can new knowledge be put to productive use if the majority of others are ignorant of this knowledge; or, what if such ideas run contrary to existing conventions? Risk emerges as a significant factor that influences people's choices.

Proposition: Individuals can incur significant costs when adopting new knowledge.

ICT costs

Another important cost that Lamberton highlights is in relation to the ICTs that facilitate the carriage, storage and processing of information. As mentioned previously he felt that an unholy alliance between politicians, some UN agencies and the private sector had formed to promote ICT investments that were not in the best interests of recipient populations. The reason why such an alliance can be sustained in a policy sense relates to hype surrounding new ICTs in terms of their ubiquity and functionality (Lamberton, 1996a). Lamberton contends that their use should nevertheless be a function of derived demand. Hence, ICT should be deployed in response to bona fide information needs rather than anticipated creation of such flows on the basis of developments that may be occurring elsewhere.

Proposition: ICT use is most effective when designed to address bona fide knowledge needs 
The cost of organisations

Another feature of information use are the organisations that are created to 'obtain and process information'. Information economists identify organisations as playing a key role in enabling information to be used most productively. For example, Arrow (1974) makes the case that organisations ultimately aim to improve the efficiencies in the ways information is obtained and processed by employing people with specialised skills. However, Arrow also points out that there are limits to such efficiency because there is an on-going need to respond to changes to the environment and the consequent need to incorporate new information into organisational processes. Lamberton concurs - capital intensity, information indivisibilities and uncertainty make organisations resistant to change. These limitations are exacerbated in a development context. Both Stiglitz and Rogers point to the innovative challenges that complicate technology transfer (Rogers, 1995; Stiglitz \& Greenwald, 2014). The costs of information are correspondingly high because problems are unique and complex. Conventional economics assumes the opposite, believing that all the hard work has been achieved elsewhere in the design of the hardware. Once organisations have been in operation for a period of time, costs relate to the difficulties that they experience in learning how to process information differently as the environment changes or new information becomes available.

Proposition: Organisations can limit the pace of development when they require time to develop effective information processing capabilities.

Proposition: Organisations can limit the pace of development if they are unable to respond to changes in the environment.

\section{Information access and equity}

Asymmetries in information access and capabilities to use information is a core area of concern in information economics (Lamberton, 1994). Therefore, the question of information differentials and asymmetries within a society in terms of possession, access and capacity to use information has implications for fully utilizing a country's human resources for development. An information perspective inevitably raises questions about equality of opportunity because the costs of discrimination, nepotism or corruption may prevent individuals from equitably gaining access to information sources that will enable them to live a better life.

Proposition: Equitable access to information and opportunities to development capabilities to use information improves development outcomes

All of these propositions point to areas that a conventional approach to development is likely to overlook. To the extent that new approaches may reveal important insights into the development process the paper proceeds to use these propositions as key analytical constructs in its investigations.

\section{Methodology}


This paper adopts a case study approach to illustrate key concepts drawn from the information costs detailed in the previous section (Yin, 2009). Case study analysis enables exploration of theory to be carried out in ways that both illustrate and inspire new theory (Siggelkow, 2007). The cases are selected from current initiatives in development agriculture in the Pacific called the All ACP Agricultural Commodities Programme (AAACP) administered by the Secretariat of the Pacific Community (SPC) and funded by the European Union (EU).

Document analysis is used to review a selection of published primary sources. The information costs elaborated in the previous section are employed as a guide in search for relevant evidence (Eisenhardt \& Graebner, 2007). A series of questions were developed that highlight each of the information costs (see Table 1). As well as this, any new insights developed in the analysis of case material were also considered.

Table 1 Guide questions used to analyse documents data

\begin{tabular}{|l|}
\hline 1. Information as capital \\
What evidence indicates that information displays capital-like qualities? \\
(structural nature, investments costs and risk, economies of scale,) \\
\hline 2. Costs to the individual \\
$\begin{array}{l}\text { Are the risks of investments that individuals are required to make in acquiring } \\
\text { and using new knowledge acknowledged? }\end{array}$ \\
\hline 3. ICTs as derived demand \\
\hline $\begin{array}{l}\text { Are ICTs presented as a quick fix? Is there evidence that ICT deployment is in } \\
\text { response to rational assessment of needs? }\end{array}$ \\
\hline 4. Uncertain roll of organisations \\
\hline $\begin{array}{l}\text { Are organisations found to limit the pace of development either in initial learning } \\
\text { phases or in maintaining practices that are no longer optimal? }\end{array}$ \\
\hline 5. Equitable access to information as well as capability development \\
\hline $\begin{array}{l}\text { Is recognition given to equitable access to appropriate information to individuals } \\
\text { to possess to access and use information? }\end{array}$ \\
\hline
\end{tabular}

The documents used for the analysis are five policy briefs that were published as part of The Secretariat of the Pacific Community's (SPC) Information and Communication Extension Program (SPC, 2010). These are as follows:

AAACP Pacific Brief No. 1 - Market Information Services (AAACP, 2011a) AAACP Pacific Brief No. 2 - Public policy support for smallholder agriculture (AAACP, 2011b)

AAACP Pacific Brief No. 3 - Certification - opportunities and challenges for Pacific producers (AAACP, 2011c)

AAACP Pacific Brief No. 4 - Supplying the tourism market - opportunities and challenges for Pacific producers (AAACP, 2011d)

AAACP Pacific Brief No. 5 - 'Whole nut' processing of coconut opportunities and challenges for the Pacific region (AAACP, 2011e) AAACP Pacific Brief No. 6 - Farmer organisations in the Pacific region (AAACP, 2011f) 
A further two supporting documents were used to provide additional background material. These are:

Agriculture for Growth: learning from experience in the Pacific:

Summary results of five country studies in Fiji, Samoa, Solomon Islands, Tonga and Vanuatu (FAO, 2010)

Embracing Web 2.0 And Social Media: a life-changing pathway for agricultural development actors (CTA, 2015)

It should be noted that analysis does not aim to undertake a comprehensive review of SPC's programs. Rather, the purpose is to illustrate the concepts that relate to information costs as defined in Table 1 and elaborated in the previous section.

\section{Case description and analysis}

The focus for the case study analysis is the All ACP Agricultural Commodities Programme (AAACP) in the Pacific, in particular, its information and communication extension (ICE) program. Funded by the European Union (EU), the AAACP aims to improve the incomes and livelihoods of agricultural producers, and to reduce income vulnerability at the producer and macroeconomic levels. The Secretariat of the Pacific Community's (SPC) Land Resources Division (LRD) provides regional facilities for the implementation of the program. Ostensibly, the ICE program presents itself as a case in which issues of information costs in relation to agriculture in the South Pacific region should be most apparent. No further justification was sought at the outset of the analysis.

\section{Information as capital: the consequences of risk}

Perhaps the first measure that one should apply to case studies is the extent to which information is recognised for its attributes as capital. Lamberton was a strong critic of initiatives that assumed information as a commodity because experts are led to overlook a number of factors that influence development outcomes.

From the list of resources detailed in he Methodology section, the document which most specifically deals with information as a specific entity is the Policy Brief on Market Information Services (AAACP, 2011a). The document's definition of information refers to market information which enables producers and other market participants to "better plan for the demand side of the market" (AAACP, 2011a, p. 1). The nature of such information relates to explicit quantities such as price and volume. Weather reports are also indicated as another important examples of market information. The role of who produces such information has traditionally been left to agricultural extension services using technologies such as newspapers and broadcast radio. 
The policy brief acknowledgement of information's structural qualities is most obvious in its treatment of complementary relationships between buyers and sellers. Awareness of possible complementarities is apparent in the idea that information flows from buyers to producers and can be reversed through the use of modern ICTs enabling one-to-one relationships to develop.

ICTs have...transformed the possibilities for market information systems...Participants can provide information as well as receive it. Buyers and sellers can communicate directly with each other (AAACP, 2011a, p. 3).

However, the writers readily acknowledge that their understanding of how market information services work in a Pacific context is deficient.

Many market information systems in many different countries have failed. To improve chances of success, market information services should be designed to respond to local or regional needs (AAACP, 2011a, p. 3).

If one assumes a commodity-view of information its possible that the size of this task will be underestimated. Stiglitz (1987) outlines the scale of this challenge by comparing this kind of problem solving to innovation. While a conventional view assumes that the hard work of developing new technology or techniques occurs in another place it fails to acknowledge the distinctiveness of local context which presents unique challenges. Stiglitz $(1987 ; 2014)$ concludes that the costs of information are high in such circumstances and are generally underestimated in conventional analysis. Given the high costs and the uncertain returns, risk emerges as a live issue. Hence, the size of this challenge is likely to be underestimated without a full appreciation of information costs.

Other features of Pacific Island development can be related to Lamberton's statements about economies of scale. These include, low volume production in a select range of commodities and remoteness of producers on distant islands. Mention is also made of poor Internet and mobile coverage which can also be understood in terms of economy of scale. Taken together with the challenges of unique environments it can be seen that scarcity of resources is unlikely to work to easily resolve of the problem of information-gaps. Hence, acknowledgement of the capital-like nature of information, that is, the one-off costs that cannot be easily re-couped, and consequent risks, is not given sufficient recognition.

\section{Information costs to the individual.}

When new information is made available in a development context by way of education or training, it is necessary to consider costs that may accrue to individuals. If steps are not taken, such costs may become a barrier to the adoption of new practices and technologies. 
One example of this relates to the train-the-trainer model of capacity building. The assumption is that resources spent on training can be used more efficiently if one individual is trained who then teaches peers.

Training for young people will have a big knock-on effect as each person who attended will go back to their association and report on the potential of the tools (CTA, 2015, p. 14).

This model of training assumes that incentives to share such knowledge exist. Ensuring one's position as a key knowledge holder, however, may encourage individuals to keep this knowledge and other attendant benefits to themselves. With few paid employment opportunities in the Pacific which have low prospects for promotion, generosity in the sharing of such knowledge is a virtue that few can afford should others benefit more from one's newly developed knowledge.

Its difficult to find other examples in the reviewed literature that acknowledges risks to individuals through their adoption of new knowledge. One has to look further afield to find examples that support the contention about costs to the individual. One illustration of the kinds of costs that may accrue to individuals is provided in an historical example of plantation development in the 1800s. The original proposition put to Pacific Islanders by colonists when establishing coconut and sugar cane plantations in the late 1700s was to work for 10-12 hours a day so that they could earn money to pay for food and other commodities. When one considers the lifestyle of Pacific Islanders at the time the proposition was nonsensical. There was plenty of food to be had from the ocean and the gardens for a fraction of the effort of required to work in the colonists plantations. As a consequence, it was difficult for colonists to convince Pacific Islanders at the time to work for wages in their plantations. The presence of Chinese, Indian, Japanese and other Pacific Islanders throughout the Pacific is testament to this basic lesson about costs as a disincentive to participate in agricultural development.

Since then, various initiatives that require farmers to deviate from traditional practices are now recognised as having had significant costs to the environment and broader community. Its noteworthy that AAACP programs recognise this:

Traditional smallholder agriculture predominates in many Pacific island countries, where it plays an important social and cultural role as well as ensuring food security. The farming systems are inherently sustainable, based on an understanding of the need to protect precious natural resources on limited land. A healthy environment is also important to other key economic sectors, for example fisheries and tourism. Public policy should therefore aim to protect the environment, retaining good practices and preserving the social and cultural role of agricultural systems, while helping farmers improve production and access to markets. This is particularly important, as in many parts of the world government policies aimed at increasing production have been shown to 
work against sustainability, for example by promoting inorganic fertilisers and toxic pesticides (AAACP, 2011b, p. 2)

While giving legitimacy to indigenous systems of knowledge the issue of costs to the individual are not actively considered.

Pacific literature provides reason to believe that the costs to individuals can be significant. Albert Wendt's (1979) classic novel Leaves of the Banyan Tree provides a vivid account of the changes that occurred within an extended family in the lead up to Samoa's independence from New Zealand. Incorporation of western values by way of new business practices and over exploitation of undeveloped forest had unintended consequences for the main character, a village chief, a newly successful businessman farmer. His embrace of western business values alienates his adult son who eventually dies from tuberculosis. The introduced disease from Europeans is symbolic of a number of impacts on the son who, after showing promise at school, develops a drinking problem and becomes an atheist. His rejection of his father's success reveals the son's deep attachment to traditional cultural values which have been surrendered by his father in pursuit of individual wealth.

\section{ICTs as a function of demand}

If one had to develop a list of development issues that annoyed Lamberton the issue of telecommunications investments would be ranked somewhere near the top (Lamberton, 1996b). Its not that he objected to new technology - just the absence of scholarship that justified the significant amounts of resources that were expended on purchasing telecommunications technology. Similarly, he held similar reservations about policy changes such as the dismantling of public ownership of various Post Telegraph and Telecommunications (PTT) departments. He saw a role for information economics to provide the necessary justifications which would enable better and more nuanced development outcomes. Instead, what he saw was an agenda largely driven by the ITU with agreement of aid donors and local politicians interested in a quick fix. So its with this kind of scrutiny that the analysis looks to the case material: firstly to what extent are ICTs presented as quick fix; and secondly, is there evidence that ICT deployment is in response to a rationale assessment of need?

Going to the first question, evidence can be found in published material from AACP that ICTs are presented as a quick fix. Two publications produced by AACP on the topic display mobile technologies and Web 2.0 as the means by which improvements in agriculture can occur. The assessment of ICT's potential is upbeat:

It would be hard to exaggerate the speed at which technological innovation is moving. Web 2.0, social media and M-Apps for agriculture play an increasingly important role in agriculture and rural development policy processes and value chain development (CTA, 2015, p. 6).

ICTs are presented as the means that will enable a change to existing agricultural practices. These are: development of partnerships; better support 
for extension services; access to open and big data; ensuring reliability and availability of high quality information; grassroots access; strengthening participation of women and young people; promotion of entrepreneurship and business; tools for advocacy; and promotion of knowledge management activities. The benefits of ICTs appear as a given fact:

ICTs have a transformative influence on farming and food production in countries where governments and policy makers are committed to developing comprehensive e-agriculture strategies (CTA, 2015, p. 7)

Each of these visions for transformation are supported by vignettes that illustrate what success looks like.

So in response to the first question it is reasonable to state that ICTs are presented as an easy choice to achieve a number of outcomes that would normally be considered quite difficult. The extent to which information costs might impinge on these pathways as discussed in the previous points is not actively considered.

The second issue seeks to find evidence of ICT deployment being guided by demand. It is interesting to note that the policy briefs produced by AACP make very little mention of ICTs. The most articulated response that can be found is in the policy brief on Market information Services which states:

New information and communication technologies (ICTs), in particular the internet and mobile phones, have transformed the possibilities for market information systems. As well as making information dissemination much easier, these ICTs allow market participants to interact with each other much more easily. Participants can provide information as well as receiving it. Buyers and sellers can communicate directly with each other (AAACP, 2011a, p. 3)

The policy brief goes on to illustrate two examples of ICT applications which implies improved cost effectiveness in communications: one is a picture of a man using a mobile phone; the second is a graphic of an information service called Info Share using mobile phone technology (p.2 \& 4). The caption states that the service is being adapted from an application developed by the United Nations Conference on Trade and Development (UNCTAD) after extensive consultation with stakeholders. This sounds like the kind of ICT deployment in response to demand that Lamberton would approve of because there is active consideration of people's information needs.

In as much as portraying ICTs as a quick fix is considered difficult to sustain, it is interesting to note that the AACP documents pay little attention to plotting a pathway for ICT adoption in response to the various policy issues. Its possible that the answer may lie in the discovery that technology is not a central issue of concern when considering development in agriculture. Alternatively, the answer may lie in developing a better conceptual understanding of the factors that mediate information sharing such as minimising information costs. 


\section{Organisations}

Recognition of information-related aspects of organisations as facilitators or constraints on development represent an area in which significant insights into the development process can emerge. The primary purpose for organisations from the perspective of information theorists is in reducing the costs associated with working with information. However, while they aim to generate efficiencies in the ways information is acquired and processed, the downside is that there is a longevity to organisations which normally makes them slow to change and perhaps outlive their usefulness. Hence organisations represent a double-edge sword where they ideally make significant contributions to development but also can complicate and confound development efforts.

The role of organisations in development is most apparent in the reviewed documents when reference is made to agricultural extension organisations which have played, and continue to play, an important role in agricultural developments in the Pacific. In one document, one such organization in Vanuatu is held responsible for the slow growth in cocoa exports and is considered a threat to the industry's future viability:

In Vanuatu, the cocoa sector development was constrained for two decades by the active involvement of the Vanuatu Commodity Marketing Board (VCMB) which acted as a marketing monopoly and constrained the ability of the sector to take advantage of the price premiums available for organic and single origin cocoa. Deregulation removed some of the constraints, but with the continued existence of the Board (albeit with an inactive role) the threat remains that it could again become active in marketing activities. This threat may be enough to reduce levels of investment in the sector (FAO, 2010, p. 39)

On the other hand, a policy brief from the AACP seems to suggest that such organisations can be created by government writ:

To be effective, public policy interventions therefore need to be based on an understanding of the specific context and constraints faced by different groups of producers. They also need to take a dynamic perspective in the sense that once a constraint is lifted, a different type of intervention may be required to support producers in meeting their next challenge (AAACP, 2011b, p. 2).

Such an understanding underestimates the challenges for organisations in developing expertise in one area and then changing focus requiring new areas of expertise. When one considers the lead-time required to train individuals (or to acquire expertise from overseas) a poor appreciation of the obdurate nature of organisations is revealed.

Private sector organisations are identified as an alternative to conventional government extension services. The reasoning for this change is 
not fully articulated. While private extension organisations are more likely to attract private sector investment one can presume that there is a clear commercial incentive to do so. In a rather confused rationale the AACP states that government extension services can help the private sector by spending public funds by way of grants and then, optimistically suggests a viable market will emerge for investors:

However, agriculture is inherently risky, and in many cases brings relatively low returns for the private investor. Public policy can promote private sector involvement by reducing the risks or increasing the returns to private sector investors. There are various financial tools to do this, for example subsidising costs of service delivery or providing grants. In many cases, this support will be needed only in the early stages of service delivery until a functioning market has developed (AAACP, 2011b, p. 2).

The cooperative has re-emerged as an alternative private sector model for farmers in the Pacific to consider. The advantages of these loosely coupled organisations relates to the spreading of commercial risk, improved lobbying potential and economies of scale. For example, access to market information can be paid for once and then distributed between members. Similar reasoning can also be applied to training as well as collective contracts with buyers. It also enables semi-subsistence farmers to participate in commercial activities while maintaining sustainability of their farming operations. This involves cultural forms of knowledge production discussed previously. Hence, organisations in this sense should be broadened to include the traditional governance structure of extended families. All of these factors can be understood in terms of reductions in information costs that organisations are potentially able to deliver.

\section{Equitable access to information}

Understanding the nature of information asymmetries was of central concern to Lamberton as an information economist. Hence, finding ways to overcome such asymmetries in both information access and the development of capabilities to use such information is an understandable cost that Lamberton has associated with development. The extent to which programs address the nature of these asymmetries becomes the focus for the analysis in this section.

The most visible initiatives designed to improve equitable access to information and the capability development are those aimed at youth and women.:

All too often, women and young people are disadvantaged, in a variety of ways, in rural areas. ICTs have an important role to play in empowering young people and women. Women are the pillar of the family in terms of smallholder agriculture and they should be provided with the resources and information they need to improve their productivity and gain access to markets. ICTs should also be used to attract young people to agriculture and ensure that they can develop their potential (CTA, 2015). 
Indeed, the identification of social media as a development tool is partly factored on the popularity of these technologies with younger people and the prospect that they may be attract agriculture as a consequence:

Agriculture development practitioners, policymakers, the private sector, government agencies and other professionals must articulate a new vision of agriculture that can be attractive to young people. ICTs are essential coordinating mechanisms in the agricultural and rural development field, and hence their integration in the delivery of agricultural information, markets and all the processes across the value chain is significant (CTA, 2015, p. 20).

There are potential pitfalls in the roll-out of ICTS that aim to assist youth and women that relate to existing social norms particularly the role of men:

Men often need to be included in the training process so that they do not feel left out, and to ensure that they do not prevent their wives from participating (CTA, 2015, p. 27).

They go onto note that its best to recognize the influence of current social structures, such as the family, as a starting point:

The main conclusion [about] gender [is] that an inclusive family-centred approach is the best way of ensuring project success and improving female farmers' access to ICTs (CTA, 2015, p. 27).

This raises the prospect that the desire to improve equity by increasing access to information may run counter to social norms. This represents a dilemma in that the desire to build on traditional forms of authority to promote sustainable use of resources may entail the kinds of asymmetries that constrain information access as well as capability development for groups such as women and youth.

An information perspective provides a unique window on equity by firstly highlighting the links that can create a clash between information access, capability development and authority. Once acknowledged the extent to which improvements in information access can be carried out within existing social norms emerges as the next task. While this represents a challenge beyond the scope of this paper an information perspective fundamentally points to the costs in obtaining and processing information. Given the prospect that individuals may be required to operate outside existing social norms and structures, the social costs can potentially be high. Equity programs that fail to recognise these possibilities are likely to fail.

\section{Discussion and Conclusion}

The paper has investigated case documents using the concepts of information costs as an analytical framework. The rationale for the application of these 
concepts is to firstly establish the value of such concepts in the analysis of development projects particularly in identifying gaps in development initiatives. Given the application of information costs to a limited set of published documents pertaining to Pacific based initiatives to improve agriculture, the findings are somewhat tentative and mainly aimed at establishing the persuasiveness of information costs as an analytical framework.

The application of information-as-capital analogy to the case material establishes a number of important principles that has implications for other information costs that are analysed. Given the one-off nature of investments in information creation, the concept of risk emerges as a key feature that an information perspective provides on development initiatives. For example, the hardware costs of initiatives may represent but a small part of the costs of creating an online market information system. Certainly, the appeal of mobile technologies are cost related where access costs are reduced when compared to more expensive hardware. However, given the uniqueness of these problems, the nature of required information is much more difficult to define. The elimination of costs in hardware provision reveals in stark clarity the need for additional efforts to define important information beyond weather reports and the latest market prices.

Also missing from this perspective are the costs of getting it wrong. Technology lock-in and switching costs - attributes of capital investment - means that risks extend far beyond the costs of hardware but relate to sunk costs in education and training. These potentially complicate attainment of development goals even though mistakes can be instructive.

Given that the costs of information creation are largely independent of economies of scale, the relative smallness of Pacific Island states emerges as a significant barrier to development. While this fact is generally recognised, its implications may be more significant than already acknowledged. It can be seen that the pooling of research efforts within regional institutions such as the SPC and USP makes sense but its clearly limited by their in ability to fully account for the highly localised nature of problem solving. Once again, the problem can be understood as a consequence of the high costs of information.

This alludes to the highly structured nature of information where local context works against the provision of generic solutions. The knowledge needs of local actors relate to highly contextualised understanding of local capabilities, social structure as well as information gaps. Its notable that broadcast radio has played a mediating role in the provision of technical information to farmers in programs in local language over many decades. The ability of a discussion between agricultural expert and presenter enables information to be conveyed in ways that accounts for the contextual knowledge in which new information is presented. The relative absence of the broadcast radio medium in the context of other ICTs in the review documents is curious.

It has to be acknowledged that the case for costs to the individual is mostly circumstantial rather than direct. The related examples provided in the 
analysis provide strong indicators that such costs are likely to exist even though not acknowledged in the reviewed documents. Incentives to participate in development initiatives must recognise possible costs to individuals that exceed those that currently exist. This can be achieved through recognition of the role that culture plays as a stable body of knowledge that has contributed to sustainable agricultural practices over a long time. Steps to minimise the imposition of such costs on individuals need to recognise the central role that traditional knowledge plays in mediating change.

The justification by which ICTs investments are promoted is another area in which costs can accrue. The planning of ICT investments on the basis of derived demand is identified by Lamberton as the kind of thinking that should be used to validate such decisions. The alternative where ICT investments are justified on the basis of political expediency or utopian visions leaves one open to the kind of criticisms Hughes (2003) made of poor growth performance on Pacific economies. Without tangible examples of improved economic performance it appears that the productivity paradox observed by Lamberton (2001) may remain a feature of Pacific economies.

Even though there are clear efforts to provide relevant pricing and weather information to farmers, an appreciation of the high cost of information may work towards better outcomes. As discussed previously, the worrying aspect to the initiatives for online market services as indicated by development planners is that more attention needs to be given to discovering the information needs of farmers. This calls for knowledge creating strategies that draw on the personal and sometimes tacit knowledge of farmers and other key actors such as those in agricultural extension services.

Alternatively, ICTs appear as part of deliberate attempts to alter existing social order. Given the importance accorded to traditional knowledge, the potential impacts of programs that seek to alter this social order are uncertain. Strategies aimed at improving the participation of women and youth, for example, appear as laudable initiatives even though appearing to challenge traditional knowledge. This of course assumes that traditional forms of knowledge systems do not have their own means of dealing with gender and youth or are unable to change in responses to such pressures. However, the basic lesson appears as one in which endogenous change has the greatest potential for success rather than that which is imposed from the outside - which many of the ICT initiatives described in the reviewed documents imply.

Organisations are found to play a contrary role when seeking to minimise information costs. While they are ostensibly designed to increase the efficiency of information handling they are also implicated in increasing information costs when they are unable to responded to changes in the environment. The naïve advice that new organisations be created by government or private sector mandate reveals poor understanding of how organisations come into being and evolve over time. For example, criticisms of established government extension services for not being able to adapt to these changes appears as harsh. Organisational change is a complex task because the kinds of expertise required 
may not be obvious. Arrow (1974) describes this in terms of the limits of organisation where the goal of achieving informational efficiency is contrary to the goal of incorporating new information into organisational processes. Hence, criticisms should not be directed at staff but should be seen as a failure of their management. Even so, given the uncertainties, the management of change is fraught with challenges that should also moderate criticisms of managers.

Lamberton argues that the need to address asymmetries in information lie at the heart of information economics. Its application to development contexts raises the possibility that issues of equity are addressed when the question of information asymmetry are also addressed. Indeed, an information perspective takes the asymmetry question a step further by looking at the opportunities that exist for people to develop capabilities in their use of information.

There is good reason to believe that increased access to information as well as opportunities to develop capabilities in using information could inadvertently increase the costs of information. This has been alluded to in the discussion of ICT initiatives that promote participation of women and youth where there is a danger that disruption to the current social order may create resistance to change. Cultural resistance to change is often cited as a barrier to development suggesting that knowledge development and diffusion processes may be at the heart of these issues. In much the same way that organisations are not naturally disposed to the incorporation of new information and expertise, the same can be said about social systems in general. It seems that programs that seek to build on the stability of current forms of traditional authority cannot seek to simultaneously invoke significant changes to this authority through the introduction of new technology including ICTs.

The vignette at the start of the paper suggests that knowledge and authority are intertwined. The analysis provides support to this contention. As authority is derived from traditional governance structures in Pacific Island societies it is likely that the process of development will be a contentious one. The constructs derived from information costs used to analyse selected documents enables the this contention to be understood as a knowledge question that permits traditional knowledge and other knowledge forms to be considered within the same analysis. The presumed superiority of western economic and scientific knowledge tends to lose its exalted status within the context of traditional knowledge systems that have successfully negotiated the vagaries of Pacific Island environments over centuries. While the prospect of returning to a pre-European state is an impractical one it is also clear that existing traditional governance structures provide the means by which new knowledge can be incorporated. To that extent, an information-based perspective outlined by Lamberton still holds considerable promise in promoting understanding of these processes well into the future.

\section{Limitations}


The paper does not provide a comprehensive review of all of SPC's programs but rather has selected a subset of literature through which the validity of information costs is analysed. On this basis, the paper has been able to provide examples where the application of these concepts to the case material yields deeper insights in to the dynamics which govern information transfer and knowledge development within a Pacific development context. To that extent, further research can be recommended particularly in relation to better incorporating cultural processes in development policy.

\section{References}

AAACP (All ACP Agricultural Commodities Programme) (2011a) AAACP Pacific Brief No. 1 - Market Information Services. Suva: All ACP Agriculture Commodities Programme, Secretariat of the Pacific Community (SPC) Land Resources Division, available from http://www.spc.int/lrd/aboutice. [Accessed 4 March 2016]

AAACP. (2011b) AAACP Pacific Brief No. 2 - Public policy support for smallholder agriculture. Suva: All ACP Agriculture Commodities Programme, Secretariat of the Pacific Community (SPC) Land Resources Division, available from http://www.spc.int/lrd/about-ice. [Accessed 4 March 2016].

AAACP. (2011c) AAACP Pacific Brief No. 3 - Certification - opportunities and challenges for Pacific producers. Suva: All ACP Agriculture Commodities Programme, Secretariat of the Pacific Community (SPC) Land Resources Division, available from http://www.spc.int/lrd/about-ice. [Accessed 4 March 2016].

AAACP (2011d) AAACP Pacific Brief No. 4 - Supplying the tourism market opportunities and challenges for Pacific producers (Vol. 4). Suva: All ACP Agriculture Commodities Programme, Secretariat of the Pacific Community (SPC) Land Resources Division, available from http://www.spc.int/lrd/about-ice. [Accessed 4 March 2016].

AAACP (2011e) AAACP Pacific Brief No. 5 - 'Whole nut' processing of coconut opportunities and challenges for the Pacific region (Vol. 5). Suva: All ACP Agriculture Commodities Programme, Secretariat of the Pacific Community (SPC) Land Resources Division, available from http://www.spc.int/lrd/about-ice. [Accessed 4 March 2016].

AAACP (2011f) AAACP Pacific Brief No. 6 - Farmer organisations in the Pacific region (Vol. 6). Suva: All ACP Agriculture Commodities Programme, Secretariat of the Pacific Community (SPC) Land Resources Division, available from http://www.spc.int/lrd/about-ice. [Accessed 4 March 2016]. 
ADB (Asian Development Bank) (2004) Responding to the Priorities of the Poor: A Pacific Strategy for the Asian Development Bank 2005-2009, available from http://www.adb.org/documents/responding-priorities-poor-pacificstrategy-asian-development-bank-2005-2009

Arrow, K. (1974)The Limits of Organization, Norton, New York.

CTA (Technical Centre for Agricultural and Rural Cooperation ACP-EU) (2015). Embracing Web 2.0 And Social Media: A life-changing pathway for agricultural development actors

available from

http://www.bing.com/search?q=embracing+Web+2.0+and+Social+medi $\underline{a} \&$ src $=$ IE-SearchBox\&FORM=IENTTR\&conversationid $=$

Eisenhardt, K. M., \& Graebner, M. E. (2007) 'Theory building from cases: Opportunities and challenges', Academy of Management Journal, 50 1, pp. $25-32$.

FAO (United Nations Food and Agriculture Organization) (2010) Agriculture for Growth: learning from experience in the Pacific, available from https://www.google.com.au/\#q=FAO.+\%282010\%29.+Agriculture+for+ Growth:+learning+from+experience+in+the+Pacific,+available+from\&gw s_rd $=\mathrm{cr}$

Firth, S. (ed.) (2006) Globalisation and Governance in the Apcific Islands. Australian National University Press Press, Canberra.

Hall, A., \& Midgley, J. (2004) Social policy for development, Sage Publications,London.

Hempenstall, P. J. (1978) Pacific Islanders under German Rule: a study in the meaning of colonial resistance, Australian National University Press, Canberra.

Higgins, B. (1994) 'Technology and economic development', in Marjoram, A. (ed.), Island Technology: Technology for Development in the South Pacific, Intermediate Technology Publications Ltd., London, pp. 29-38.

Huffer, E. (2006) 'Regionalism and Cultural Identiity: Putting the Pacific Back into the Plan', on Firth, S. (ed.), Globalisation and Governance in the Pacific Islands, ANU E Press, Canberra, pp. 43-55..

Hughes, H. (2003) Aid has failed the Pacific (33), available from http://www.cis.org.au/IssueAnalysis/ia33/ia33.htm

Jussawalla, M., Lamberton, D. M., \& Karunaratne, N. D. (Eds.). (1988) The Cost of Thinking: Information Economies in Ten Pacific Countries, Ablex Publishing Corporation Norwood, New Jersey.. 
Kelsey, J. (2004) Big Brothers Behaving Badly: The Implications for the Pacific Islands of the Pacific Agreement on Closer Economic Relations (PACER), available fromhttp://www.arena.org.nz/bigbully.pdf

Lamberton, D. M. (1988)'The cost of thinking', in M. Jussawalla, D. M. Lamberton, \& N. D. Karunaratne (Eds.), The Cost of Thinking: Information Economies in Ten Pacific Countries,Ablex Publishing Corporation, Norwood, New Jersey, pp. 3-6.

Lamberton, D. M. (1994) 'The Information Economy Revisited', in R. E. Babe (Ed.), Information and Communication in Economics, Kluwer Academic Publishers, Dordrecht, pp. 1-33..

Lamberton, D. M. (1996a) 'Infrastructure: A nebulous and overworked construct?', International Journal of Technology Management, 12, 5/6, Special Issue, pp. 696-703.

Lamberton, D. M. (1996b) A telecommunications infrastructure is not an information infrastructure', Prometheus, 14, 1, pp. 31-38.

Lamberton, D. M. (1998) 'Information: pieces, batches or flows?', in Dow, S.C. and Earl, P.E. (Eds), Economic Organization and Economic Knowledge: Essays in Honour of Brian J. Loasby (Vol. I), ,Edward Elgar, Cheltenham, pp, 209224.

Lamberton, D. M. (2001) 'An information infrastructure for development', Prometheus, 19, 3, pp. 223-230.

Macdonald, S., \& Nightingale, J. (1999) 'A questioning career', in Macdonald, S. and Nightingale, J. (Eds.), Information and Organization: A Tribute to the Work of Don Lamberton, Elsevier Science B. V., Amsterdam, pp. 3-15.

Marschak, J. (1966), 'Economic planning and the cost of thinking', in Marschak, J. Economic information, decision, and prediction, selected essays (Vol. II), . D. Reidal, Boston, pp. 193-200)..

Midgley, J. (2003) 'Social development: The intellectual heritage', Journal of International Development, 15, 7, pp. 831-844.

Pusey, M. (1991) Economic Rationalism in Canberra, Cambridge University Press, Sydney..

Rogers, E. M. (1995) Diffusion of Innovations (4th ed.), The Free Press, New York.

Schwass, R. H. (1983) Problems of agricultural extension and development in the South Pacific. Paper presented at the Pacific Science Congress, University of Otago, Dunedin,1-14 February 1984, available from http://www.fftc.agnet.org/library.php?func=view\&id=20110725162448 \&type_id $=4$ 
Siggelkow, N. (2007) 'Persuasion with Case Studies', The Academy of Management, 50, 1, pp. 20-24.

SPC (The Secretariat of the Pacific Community) (2010) 'Information, Communication \& Extension (ICE)' available from http://www.spc.int/lrd/about-ice. [Accessed 4 March 2016].

Stiglitz, J. E. (1987) 'Learning to learn, localized learning and technological progress'. in Dasgupta, P. andStoneman, P. (Eds), Economic policy and technological performance, Cambridge University Press, Cambridge, pp. 125-144..

Stiglitz, J. E., \& Greenwald, B. C. (2014) Creating a learning society: a new approach to Growth, Development, and Social Progress, Columbia University Press, New York.

Streeten, P. (1993), 'The Special Problems of Small Countries', World Development, 21, 2, pp. 197-202.

Tibben, W. J., \& Tielu, A. (2007) 'Innovation strategy for the Pacific Islands in the new millenium: mixing science with tradition', in Turpin, T. and Krishna, V.V. (Eds.), Science, Technology Policy and the Diffusion of Knowledge: Understanding the Dynamics of Innovation Systems in the Asia Pacific, Edward Elgar, Cheltenham, pp. pp.378-403.

UNDP (United Nations Development Program) (1999) Pacific Human Development Report 1999: Creating Opportunities, available from https://www.google.com.au/\#q=UNDP+\%28United+Nations+Developme nt+Program\%29.+\%281999\%29+Pacific+Human+Development+Report+ 1999:+Creating+Opportunities,\&gws_rd=cr

Wendt, A. (1979). Leaves of the Banyan Tree, Penguin Books, Auckland.

Yin, R. K. (2009) Case study research: design and methods, SAGE Publications, Thousand Oaks. 